\title{
Editorial
}

\section{El ausentismo cuestiona al sistema político}

Esta vez el alcance atribuido a las elecciones presidenciales fue más modesto. Así como las de 1994 fueron saludadas como "las elecciones del siglo", creyendo que la democracia era cosa hecha, las de 1999, pese a ser las últimas del milenio, no despertaron tanto entusiasmo. El desinterés y la indiferencia afloraron pronto, al inicio de la campaña electoral, y culminaron en un elevado ausentismo, el cual se aproximó al 65 por ciento.

ARENA no encontró una oposición real y ganó en primera vuelta, pero se encuentra ante desafios que ponen en sordina su triunfo electoral. En realidad, ARENA no ganó las elecciones, sino que más bien el FMLN las perdió. Este tuvo en sus manos la posibilidad del triunfo, pero la dejó escapar. Ahora bien, más allá de quién perdió y quién ganó, el ausentismo es un dato que no debiera pasar desapercibido.

\section{Ausencia de una oposición real}

Los resultados de las elecciones se decidieron, en la práctica, en octubre de 1998, varias semanas antes de que la campaña misma comenzara. Los dos hechos claves fueron el recorrido que Francisco Flores hizo por el país para dialogar con la población y el debilitamiento que las elecciones primarias ocasionaron en las filas del FMLN. Así como Flores dio los pasos estratégicos indispensables para triunfar, la coalición FMLN-USC no pudo hacer otro tanto. La oposición, y en particular el FMLN, no pudo contrarrestar la influencia de estos dos hechos en los resultados finales, durante el desarrollo de la campaña electoral.

Con todo, la campaña electoral auguraba algunas novedades. A diferencia de otras ocasiones, los partidos políticos se mostraron dispuestos a cumplir el 
compromiso ya de rigor de desarrollar una campaña electoral de altura, incluyendo la ausencia de insultos y la eliminación de conductas indecorosas, y la discusión de los problemas nacionales. ARENA y el FMLN-USC, cada uno a su manera, pusieron énfasis en sus respectivos planes de gobierno, en un vano intento por privilegiar las ideas acerca del gobierno sobre el personalismo inevitable de las candidaturas presidenciales. Al final, la impresión general -en buena medida, creada por los medios de comunicación social- es que la campaña fue, en efecto, de altura y seria, aunque irrelevante. En la práctica, el ritmo lo impuso ARENA, que arrastró consigo a los otros partidos políticos.

La imagen que éstos proyectaron en los grandes medios de comunicación social fue muy cuidada y correcta. Mantuvieron las formas y la buena educación casi hasta el final. Quienes hablan de altura lo hacen influenciados por esta proyección. Pero los mitines de ARENA en las plazas públicas fueron otra cosa muy distinta. En ellos, este partido se dedicó a insultar a su contrincante principal por todo el país. En este segundo discurso de campaña, ARENA, utilizando términos duros, no sólo descalificó al FMLN y a sus candidatos, sino que además les atribuyó, unilateralmente, la destrucción y la muerte dejadas por la guerra - olvidando que él y sus dirigentes estuvieron asociados a la Fuerza Armada y a los escuadrones de la muerte.

La coalición electoral FMLN-USC, por su parte, no sólo hizo caso omiso de este discurso, dejando así el campo libre a ARENA, sino que tampoco explotó el desgaste de los diez años de gobierno de su contrincante principal. Temas como la corrupción, la inseguridad, el desempleo, etc., no recibieron mayor atención por parte de los políticos del FMLN ni por los de la Unión Social Cristiana. De esta manera, al no confrontar las realidades políticas y sociales, la coalición FMLN-USC dejó un vacío que no fue llenado por nadie.

Las buenas formas, sin embargo, no se pudieron mantener hasta el final de la campaña. En las últimas semanas, los políticos las abandonaron y retomaron las antiguas formas del discurso político salvadoreño. Antiguas, pero actuales, porque es el lenguaje habitual de los diputados en la Asamblea Legislativa y de los políticos en sus intervenciones públicas. Este cambio de discurso se debió, en parte, a la inseguridad de aquellos candidatos presidenciales que se colocaron a sí mismos a la cabeza de las preferencias electorales, pero cuyas expectativas no se veían confirmadas por las encuestas de opinión; pero, en parte, también obedeció a que éstos no pudieron resistir a su propia naturaleza que, al final, terminó imponiéndose, mostrando lo que son en realidad.

De las palabras, algunos pasaron a los hechos. Hubo destrucción de propaganda y algún que otro incidente violento. El Centro Democrático Unido, que pronto mostró en algunas encuestas de opinión un crecimiento no esperado, fue objeto del ataque de una organización fantasma, empeñada en recordar a la opinión pública, en una serie de desplegados en la gran prensa, 


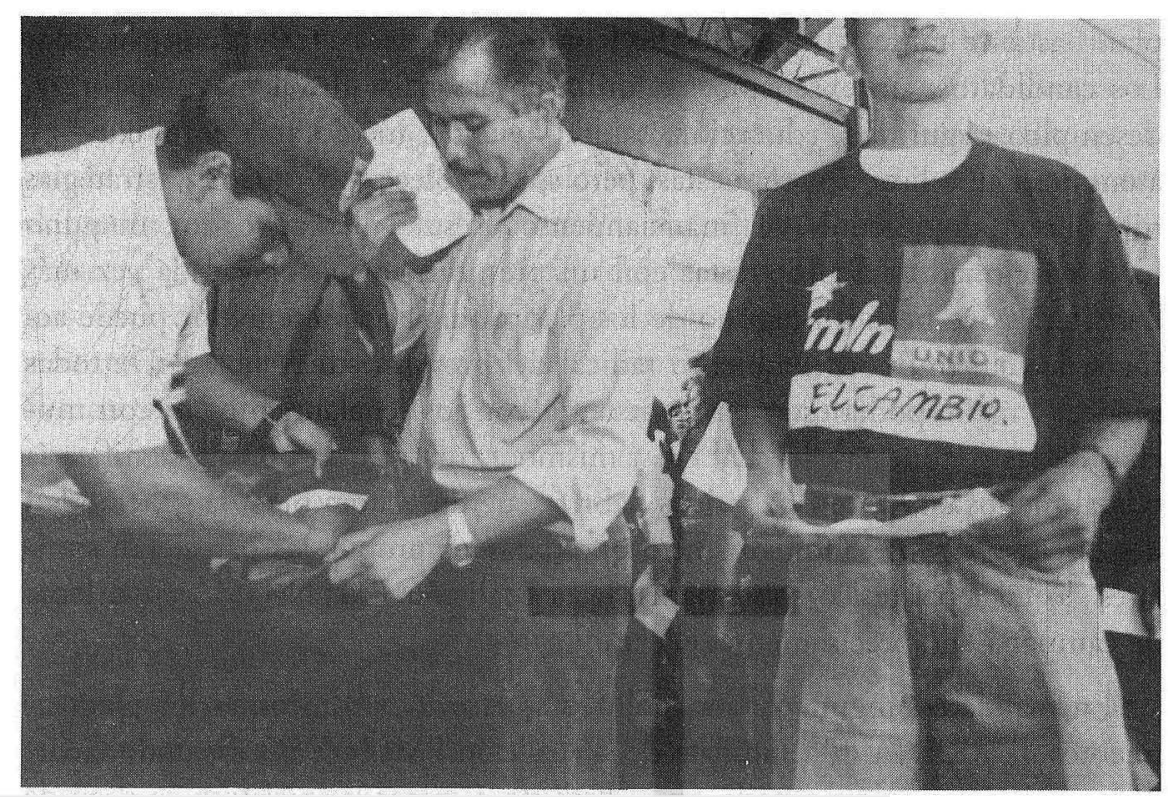

que Rubén Zamora estuvo asociado al FMLN durante la guerra, que tomó parte en los primeros diálogos y que, presuntamente, fue beneficiario de la piñata sandinista. Otro blanco de los partidos políticos perdedores fueron las encuestas del Instituto Universitario de Opinión Pública de la UCA. No obstante que los resultados de otras tres encuestas fueron similares a los de la UCA, sólo ésta fue objeto del ataque de los candidatos cuyas expectativas no se veían confirmadas.

La campaña de Francisco Flores fue la que más evolucionó en este sentido. El candidato de ARENA comenzó mostrándose amable, cercano y educado; pero cuando obtuvo el respaldo del partido y su popularidad aumentó hasta ocupar el primer lugar en las preferencias electorales, se mostró arrogante y prepotente. Las buenas formas sólo parecen haber sido una fachada útil para hacerse aceptable a la opinión pública y asegurarse así que el partido aceptara su candidatura, posibilidad ante la cual vaciló, en un primer momento. Sin embargo, si Flores piensa gobernar a partir de una serie de concertaciones nacionales amplias, ya ha minado sus posibilidades antes de comenzar a gobernar al mostrar que no hay diferencias sustanciales entre la vieja y la nueva dirigencia de ARENA. Esta es una advertencia que no debe pasar desapercibida, sobre todo para aquellos que piensan que esta candidatura es reflejo de la reforma de ARENA.

\section{Ausencia de la problemática nacional}

La discusión de los problemas nacionales - otro compromiso de campaña de los partidos políticos - no tuvo lugar. Ni siquiera la coalición FMLNUSC, cuyo discurso dio mucha importancia al plan de gobierno, analizó la problemática de la realidad nacional con seriedad. De hecho, presentó su 
plan bastante tarde, a mediados de febrero, pocos días antes de la elección. Los candidatos, sin excepción, se limitaron a señalar problemas - pobreza, desempleo, seguridad, educación, salud, vivienda, medio ambiente, etc. - y a enunciar una lista de propuestas, pero sin establecer prioridades, estrategias ni, sobre todo, fuentes de financiamiento. Resulta llamativo que ninguno haya relacionado sus propuestas con un presupuesto nacional cada vez más deficitario. De hecho, ninguno de los planteamientos presentados puede actualizarse sin un reordenamiento radical del presupuesto nacional. De todas maneras, nadie podía estar en desacuerdo con los señalamientos ni con muchas de las propuestas, lo cual en sí mismo es un avance, porque significaría que al menos en los temas básicos habría acuerdo. Ahora bien, la generalidad del discurso de los candidatos hizo que todas las propuestas parecieran similares, lo cual perjudicó sobremanera a la coalición FMLN-USC, cuyo lema de campaña era, precisamente, el cambio.

En realidad, ningún partido político se atrevió a confrontar los planteamientos de ARENA. El candidato de la coalición FMLN-USC, Facundo Guardado, quien por su trayectoria era el llamado a tomar la iniciativa, se negó de manera sistemática a confrontar a ARENA y más bien se esforzó por despojar su discurso de toda ideología de izquierda y por parecer próximo a la derecha. En cambio, el Centro Democrático Unido mostró tener ideas más claras y articuladas sobre su propuesta, aunque no tuvo tiempo para difundirlas. Es paradójico que el partido que se postulaba como el promotor ideal del cambio haya sido el que más se haya esforzado por ocultar su izquierdismo, es decir, aquello que lo podría haber vuelto atractivo para la mayoría de la población que aboga porque ARENA no siga gobernando y por transformaciones sociales importantes. Preocupado en exceso por la gobernabilidad, el candidato de la coalición perdió la perspectiva electoral. El poder que el FMLN busca para impulsar los cambios proviene de los votos y no de negociaciones o acuerdos que pueda concertar con la cúpula de la derecha. Los votos son los que le darán la capacidad para negociar con la derecha desde una posición de poder y no al revés. Es iluso pensar en negociar antes de tener poder.

Frente a la indefinición de la coalición FMLN-USC, Zamora y su Centro Democrático Unido emergieron con fuerza y le quitaron votos a aquélla, presentándose como una alternativa. La postura de centro izquierda de Zamora, más definida de lo que parece y percibida como tal por la derecha con bastante precisión y también por una parre de la población, permirió a su coalición obtener un cómodo tercer lugar en las preferencias electorales, pese a haber entrado tarde en la contienda, a ser su primera participación como tal y a contar con pocos recursos. El potencial demostrado para captar votos puede modificar el futuro político inmediato del pais, siempre y cuando el Centro Democrático Unido fortalezca su identidad de izquierda. 
No obstante las apariencias, en las ofertas electorales de ARENA y de la coalición FMLN-USC se pueden encontrar algunas diferencias. El programa de las alianzas de ARENA es claramente de derecha. Y, en la práctica, no se puede esperar otra cosa de este partido. Su derechismo se constata al plantear el fortalecimiento de la reforma fiscal y financiera, impulsada por los dos gobiernos anteriores, lo cual significa reconocer que la política económica no necesita rectificaciones en este punto; la conservación de la asistencia crediticia para el desarrollo de los programas sectoriales al nivel actual, lo cual es claramente insuficiente; continuar con la desgravación arancelaria, desprotegiendo aún más a las empresas agropecuarias e industriales, sin brindarles oportunidades reales para reconvertirse; el aumento de las exportaciones, pero sin explicar cómo los productos salvadoreños serán más competitivos; y la descentralización como traspaso de la prestación de los servicios básicos a los municipios.

Dado que no es posible esperar otra cosa, el derechismo de ARENA no es cuestionable. Lo cuestionable es que la coalición FMLN-USC no haya impulsado un planteamiento de izquierda. Los puntos más destacados de su oferta fueron la reforma del sistema financiero, el desarrollo del sector rural y local, la protección al consumidor y la promoción de la democratización y la participación ciudadana. Algunos temas importantes como el desarrollo de la industria y de la agricultura no fueron tratados con la profundidad necesaria. Otros temas cruciales como la globalización y el neoliberalismo simplemente no fueron tratados. Semejante inconsistencia fue aclarada por un alto dirigente del FMLN, quien dijo, después de la elección, que la plataforma del partido había sido formulada para salir del paso.

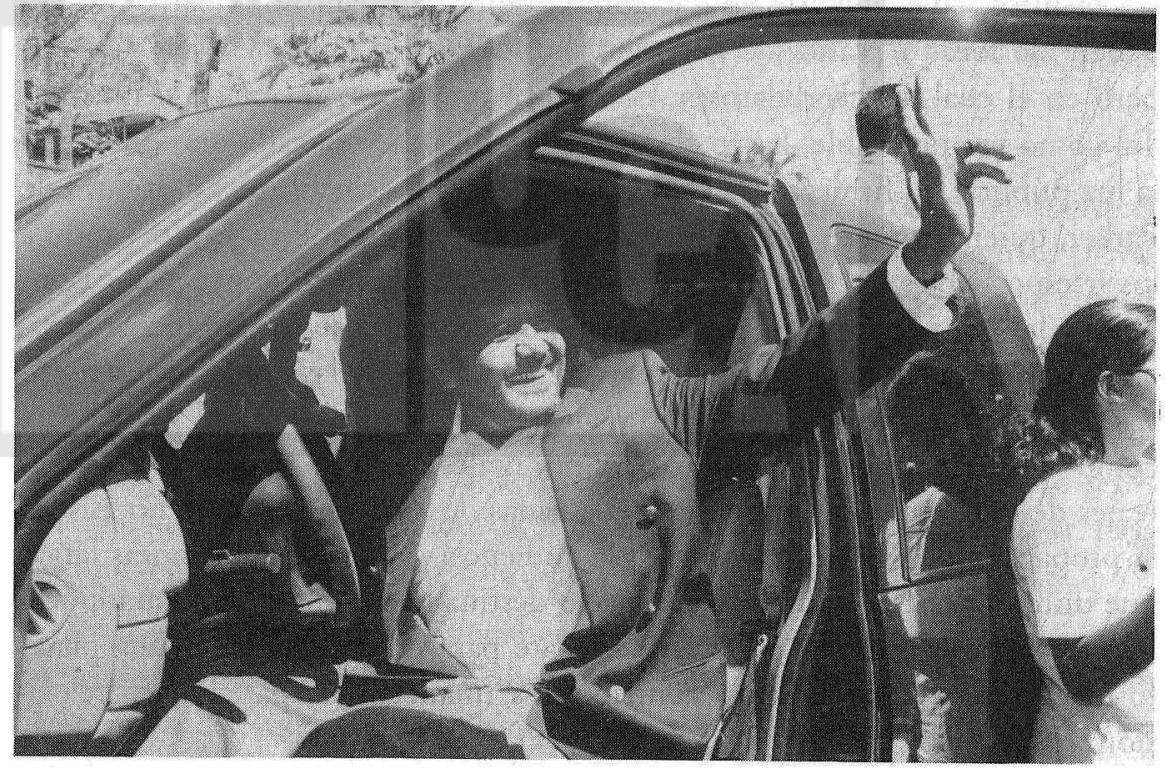


No obstante estas diferencias, los programas de ambos partidos coinciden en no haber profundizado en aspectos importantes de la realidad nacional, como el sesgo antiexportador de las políticas económicas, la dependencia de las remesas familiares, la articulación de la política de reconversión productiva con la política económica en general, las prioridades en educación, salud y vivienda, y sobre todo las posibilidades de la hacienda pública para financiar la ampliación y consolidación de estos programas. Tampoco se detuvieron a analizar el papel de la empresa privada en la prestación de los servicios públicos, cuya voracidad se aprovecha de un Estado débil e impotente, que no puede controlarla ni exigirle mayor cobertura y mejor calidad.

La abstracción del discurso político colocó en el centro de la campaña electoral el debate formal entre los candidatos presidenciales. Como éstos no discutían sus propias propuestas, pareció que había que reunirlos y forzarlos a explicarlas, en un intento por conocer las diferencias entre ellas y otorgar así mayor sentido al voto. De nuevo, ARENA logró imponerse sobre los otros partidos, los medios de comunicación a favor del debate y la opinión pública. A pesar de las presiones a favor del debate, ARENA se negó sistemáticamente a participar, porque éste no era determinante para su triunfo electoral.

El gran ausente en los planteamientos de los partidos políticos y en el debate público fue el trabajo de la Comisión Nacional de Desarrollo.

De todas maneras, el debate tuvo lugar, sin la participación de Flores y sin insultos, cosa que éste aducía como argumento para no debatir. Fue un debate de ideas y planes de gobierno, limitado si se quiere en sus alcances, pero en el cual los candidatos se esforzaron por dar lo mejor de sí mismos. Tal como era previsible, las fotalezas y las debilidades de cada uno salieron a la luz pública: la firmeża y la claridad de ideas y el derechismo autoritario de Parker, quien propuso, entre otras cosas, fortalecer la familia, pero negando a los irresponsables el derecho constitucional a la identidad; la perspectiva popular y las vaguedades de Guardado, temeroso de que sus ideas no fuesen aceptadas por el poder económico del país; el derechismo y las tendencias represivas de García, quien calificó los crímenes de la Guardia Nacional y ORDEN como "imperfecciones"; las soluciones puntuales de Ayala para los problemas reales de la gente; y las respuestas articuladas de Zamora. Aunque no asistió, la propaganda de Flores machacó a la audiencia durante las dos horas largas que duró el debate, saturando el espacio destinado a comerciales. Paradójicamente, se negó a tomar parte en el debate para no proporcionar una plataforma a sus adversarios, pero contribuyó a financiar su aparición en televisión. 
Si bien la experiencia resultó positiva, no fue del todo apropiado centrar la dinámica de la campańa en un debate, porque los partidos políticos deben captar votos con propuestas y candidatos convincentes y creibles; porque la difusión masiva de sus ideas no pasa necesariamente por una discusión formal; porque, en las circunstancias actuales del país, era difícil que un foro al estilo estadounidense diera votos a un determinado partido político; porque ARENA no puede mostrarse favorable a algo que no practica en su interior, excepto en su Consejo Ejecutivo Nacional, en cuyo seno sí discute en serio, pero en secreto. En pocas palabras, el debate de la problemática nacional difícilmente puede llevarse a cabo, sin una mentalidad democrática.

El gran ausente en los planteamientos de los partidos políticos y en el debate público fue el trabajo de la Comisión Nacional de Desarrollo. Es incomprensible que ARENA no haya retomado las bases ni los temas claves para el plan de nación, siendo una de las iniciativas más prometedoras del presidente Calderón. Aunque, por un lado, puede que haya sido mejor no contaminarla con la contienda electoral; por el otro, ambos documentos recogen una visión del país, de sus problemas y de sus posibles soluciones mucho más ajustada a la realidad que la plataforma de las alianzas de Flores. Es comprensible que la coalición FMLN-USC no haya querido identificarse con unos planteamientos formulados en el seno de una comisión presidencial, designada por un gobierno de ARENA; pero resulta incomprensible que sus propuestas no hayan ido más allá de las de dicha comisión. Las bases y los temas claves para el plan de nación son bastante más progresistas que la plataforma electoral de la coalición.

Flores fue elegido por no más del 18 por ciento de la población en edad de votar, equivalente a menos de la tercera parte de los ausentistas, la verdadera mayoría.

El debate político, en sentido estricto, es una práctica extraña al quehacer de la clase política y gobernante e incluso de los grandes empresarios privados y los medios de comunicación social. No se discuten ideas, sino que se intenta descalificar al adversario esgrimiendo argumentos que cuestionan su credibilidad personal. Las propuestas, las opiniones o las críticas contrarias responderían invariablemente a motivaciones perversas u oportunistas, pasando por alto que éstas podrían responder a análisis y puntos de vista o tener fundamentos teóricos y prácticos. La transformación de El Salvador pasa inexorablemente por un debate amplio y abierto de la realidad nacional.

La ausencia de insultos, lo cual en sí mismo es positivo, y la falta de una discusión seria de la realidad nacional hicieron anodina la campaña electoral. La reacción del cuerpo electoral, que no llegó a entusiasmarse por algo ininteligible y por figuras incapaces de mostrar una visión realista del país y de 


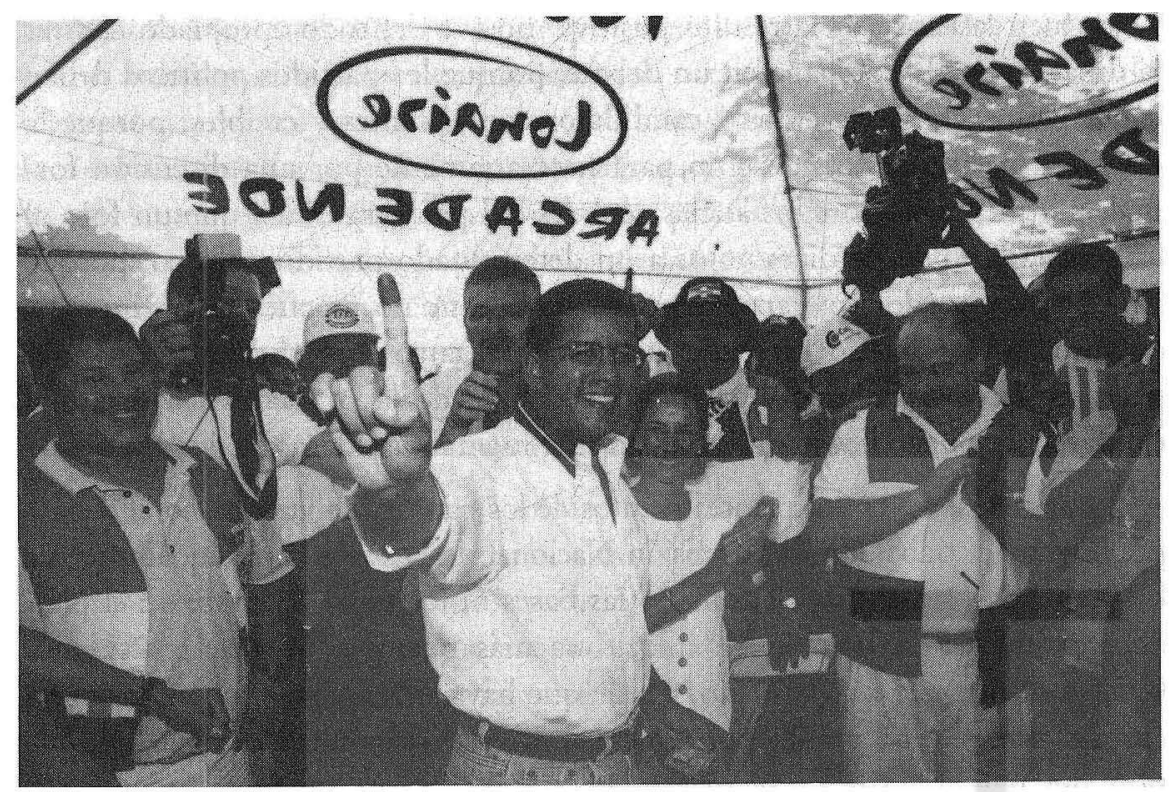

generar confianza y credibilidad, fue la pasividad y la abstención. De esta manera, ARENA consiguió con un sólo golpe desmovilizar a la mayoría de la población, lo cual le ha dado buen resultado hasta ahora, y paralizar al FMLN. La campaña gris de la coalición FMLN-USC no podía poner en movimiento a la mayoría de quienes desean un cambio de gobierno.

\section{El ausentismo cuestiona el sistema político}

La mayor parte de la población querría, en efecto, un cambio de gobierno y una transformación del ordenamiento social vigente, pero no consideró que la coalición FMLN-USC fuera capaz de impulsarlos. El FMLN creyó, de alguna manera, que la conquista electoral de 1997 era una garantía segura del aumento de su caudal de votos. De hecho, a mediados de 1998, se encontraba al mismo nivel de preferencias electorales que ARENA, lo cual parecía confirmar tal creencia. Sin embargo, a partir de ahí, una brecha que resultó insalvable lo fue alejando del primer lugar, hasta dejarlo a 23.08 puntos porcentuales (51.96 de ARENA contra 28.88 por ciento del FMLN-USC). El FMLN no comprendió que su fuerza no radicaba tanto en ser aceptable para el orden establecido como en ser el único partido político con capacidad para hacer frente a ARENA y que para ello era necesaria una alianza mucho más amplia que la coalición con la Unión Social Cristiana.

Prisionero de sus propios recelos y fantasmas, el FMLN perdió credibilidad como alternativa de gobierno y no supo sintonizar con los deseos de las mayorías populares que quisieran empleo estable, mayor poder adquisitivo y más seguridad personal y social. El fracaso del FMLN es causa de frustración para quienes concurrieron a las urnas a votar por él, convencidos de una victoria segura —aunque al perder sólo 20 mil votos respecto a 1997, su 
derrota no es tan aparatosa como se podría haber esperado, dada la campaña electoral desarrollada-, y para muchos más que se abstuvieron - quienes también quisieran cambios sociales radicales, pero que no consideran que el FMLN actual pueda impusarlos. De esta manera, la derrota del FMLN trasciende a sus propias bases y siembra desesperanza en más gente de la que su dirigencia probablemente se imagina. $Y$ es que, al parecer, el FMLN aún no parece haber realizado la responsabilidad histórica que pesa sobre sus hombros, en cuanto depositario de las esperanzas populares. El ser depositario de dichas esperanzas no le garantiza que cuente de antemano con el voto masivo de la población, tal como ha quedado evidenciado en la elección del 7 de marzo. La relación entre voto y expectativa popular no es mecánica. Para contar con el voto masivo, el FMLN debe ganarse la voluntad y la confianza de quienes están a favor de los cambios sociales.

El debate político, en sentido estricto, es una práctica extraña al quehacer de la clase política y gobernante e incluso de los grandes empresarios privados y los medios de comunicación social. No se discuten ideas, sino que se intenta descalificar al adversario esgrimiendo argumentos que cuestionan su credibilidad personal.

Los resultados electorales han puesto nueva urgencia a la cuestión de su identidad como partido de izquierda. El problema fundamental que el FMLN debiera dilucidar antes de entrar en la próxima campaña electoral para elegir diputados y alcaldes no versa tanto sobre la ortodoxia marxista, sino acerca del papel que le corresponde asumir como partido de las mayorías populares, en una democracia en ciernes, sumida en la corriente neoliberal. Esta discusión ha venido presionando al partido desde hace meses, pero de la misma forma, éste la ha venido postergando, quizás en un vano intento por ganar tiempo. Las elecciones presidenciales recién pasadas ya demostraron que las candidaturas, aunque electas de manera democrática, no son capaces de dar identidad a un partido dividido por corrientes encontradas; asimismo, dejaron una dura lección sobre las consecuencias de participar en una elección arrastrando divisiones internas.

El triunfo de ARENA no se explica sólo por la ausencia de un contrincante verdadero, aunque no desaprovechó la oportunidad que la oposición le brindó gratuitamente. El ausentismo de cerca del 65 por ciento de la población es un factor determinante en la victoria del partido de gobierno. Flores fue elegido por no más del 18 por ciento de la población en edad de votar, equivalente a menos de la tercera parte de los ausentistas, la verdadera mayoría. Sin duda, el ausentismo afectó a todos los partidos, pero ARENA fue el menos afectado y no porque sea un partido de masas, sino porque es el que 
cuenta con más recursos para atraer a la minoría que concurrió a las urnas: más hombres que mujeres y más jóvenes que en las elecciones anteriores, en su mayoría pertenecientes a las clases alta y media, que son, además, las más educadas. El nuevo gobierno no cuenta, pues, con el respaldo masivo de la población salvadoreña.

Es muy probable que una votación masiva hubiera resultado contraproducente para la aestrategia electoral de ARENA. Un sistema electoral excluyente y complejo, en el fondo, sigue siendo una ventaja para este partido, lo cual explica su tenaz oposición a reformar el código electoral de tal manera que facilite la votación masiva. Pero el ausentismo masivo no sólo es un rechazo a ARENA y sus candidatos, sino que, además, es una manifestación del desencanto de la población con el sistema político, la clase política, el gobierno e incluso las instituciones públicas —en concreto, el Tribunal Supremo Electoral-, de indiferencia ante la práctica política y también de rechazo al FMLN. El ausentismo del 7 de marzo es la manifestación hasta ahora más contundente del descrédito y del desprestigio del quehacer de los políticos ante los ojos de la población. La mayor parte, la que no concurrió a las urnas, está convencida de que el ejercicio del sufragio no influye en el rumbo del país. Entre ella predomina la convicción de que ganase quien ganase la elección pasada, El Salvador seguiría lo mismo. La oposición, y en particular el FMLN, no pudo transformar esta apatía predominante en apoyo masivo. En realidad, para la mayoría de la población, el FMLN actual ocupa el cuarto lugar entre las alternativas que podrían cambiar El Salvador.

El problema fundamental que el FMLN debiera dilucidar antes de entrar en la próxima campaña electoral para elegir diputados y alcaldes no versa tanto sobre la ortodoxia marxista, sino acerca del papel que le corresponde asumir como partido de las mayorías populares, en una democracia en ciernes, sumida en la corriente neoliberal.

Al final, la mayoría se vio forzada a escoger entre el mal menor o no votar. La mayor parte de quienes concurrieron a las urnas prefirieron lo seguro y dieron otra oportunidad a ARENA - por simpatía hacia el partido (26.6 por ciento) y su candidato (15.9 por ciento), por el trabajo de aquél (13.1 por ciento) y por las propuestas de campaña (13.7 por ciento). Son los mismos que argumentan que el FMLN aún no está preparado para gobernar. En cambio, quienes votaron por la coalición FMLN-USC - por el cambio (46.6 por ciento), por simpatía hacia el candidato (17.4 por ciento) y por el trabajo del partido (14.9 por ciento) — pensaron que habría que darle esa 
oportunidad, pero eran una minoría. La diferencia la hizo el candidato de ARENA, que supo explotar su aparente distanciamiento de los vaivenes de la vida política nacional, convirtiendo en novedad lo que, en realidad, era desconocimiento.

El triunfo de ARENA debiera ser tomado, pues, con cautela, tanto por su dirigencia como por su nuevo gobierno. No es arrollador, aun cuando se haya producido en la primera vuelta. Ni es expresión de una voluntad popular masiva, aunque haya obtenido el 51.96 por ciento de los votos válidos. Tampoco es un simple resultado de la desidia o la indiferencia, sino que responde a diversos factores que, al final, se concretizan en un rechazo a las ofertas hechas por los partidos políticos. En realidad, ARENA sólo ha recuperado el voto que, descontento, emigró en 1997. El total de votos captados en 1999 es similar al de 1994.

El descenso en las preferencias electorales experimentado en los comicios de 1997 alarmó a ARENA con sobrada razón. En reacción a este descalabro político, el partido se preparó de manera concienzuda para las siguientes elecciones: hizo cambios en su dirección, recompuso sus fuerzas, manejó bien sus divisiones, lanzó un candidato supuestamente no vinculado a su pasado y representantivo de una nueva generación de políticos de derecha e invirtió una suma elevadísima en la campaña electoral —cerca de 50 millones de colones. Con gran habilidad, Flores ocultó su irrelevante carrera de funcionario en los dos primeros gobiernos de ARENA, tomó distancia del cuestionado gobierno de Calderón, se presentó interesado en escuchar a la población, cosa que ninguno de sus predecesores - y contrincantes- hizo, e impuso su agenda personal en la campaña electoral.

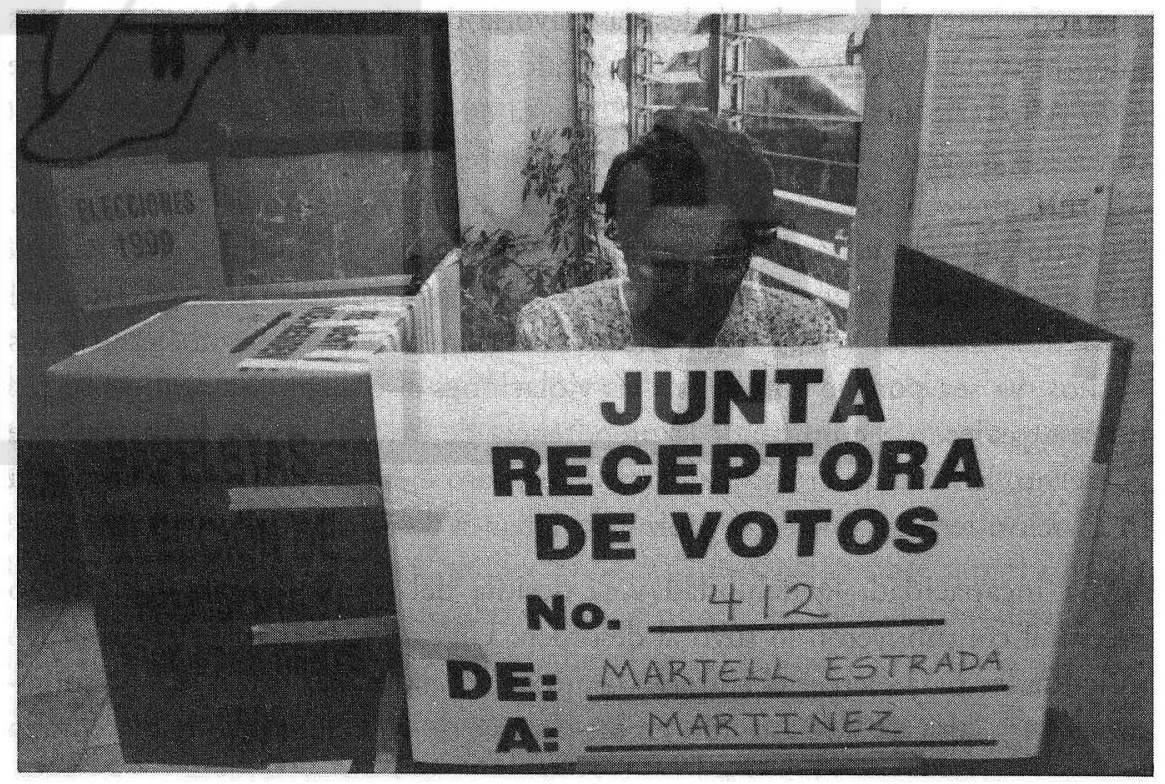


No obstante estos esfuerzos y cambios, ARENA sólo pudo recuperar el voto de 1994. Cuantitativamente, esto significa que cada voto le habría costado un poco más de 80 colones y cada punto porcentual, cerca del millón de colones. En realidad, una inversión muy alta para un resultado tan limitado y, hasta cierto punto, poco efectivo, porque el 61.7 por ciento de quienes votaron el 7 de marzo decidió su voto antes de la campaña electoral y el 13.4 por ciento lo hizo ese mismo día. Sólo el 24.3 por ciento decidió su voto durante el desarrollo de la campaña. Cualitativamente, este resultado podría estar indicando que ARENA ya ha dado de sí todo lo que podría dar. Tanto su proyecto polírico anticomunista, antidemocrático y confrontativo como su maquinaria electoral estarían mostrando señales de agotamiento.

Un ausentismo tan elevado - comparable sólo con el de Guatemala y Estados Unidos- no sería muy grave si ARENA comprendiera sus implicaciones para gobernar por tercera vez consecutiva y para relacionarse con la sociedad y las otras fuerzas sociales. El peligro estriba en el envalentonamiento que pueda producir en sus filas el resultado electoral favorable de 1999. La tendencia a interpretarlo como un cheque en blanco puede resultar irresistible. ARENA ha ganado la presidencia de la república, pero el pueblo salvadoreño y la democracia salvadoreña han perdido. El escaso respaldo con el cual ARENA inicia su tercer gobierno significa que la población no se encuentra inclinada a concertar alianzas a partir de las cuales Flores piensa gobernar.

Las elecciones fueron pacíficas y ordenadas, tal como ha sido reconocido por las autoridades salvadoreñas y la mayoría de los observadores nacionales y extranjeros, pero sólo en el área metropolitana del gran San Salvador, donde, curiosamente, la vigilancia fue más estrecha. En el interior no hubo el mismo orden. Los informes de los corresponsales de YSUCA registraron una serie larga de irregularidades, la mayoría de ellas protagonizadas por los miembros de ARENA, incluso por alcaldes. Todos los partidos, pero sobre todo ARENA, hicieron propaganda abierta en los sitios de votación, orientaron a los electores y protagonizaron incidentes diversos. Varios militantes de ARENA fueron descubiertos votando más de una vez, entre ellos un alcalde. Otro de ellos fue acusado de comprar votos. Algunos militantes de ARENA fueron vistos con más de un carné electoral. Los representantes del Tribunal Supremo Electoral restaron importancia o simplemente desconocieron estos hechos, ya sea porque aprobaban las violaciones al código electoral o porque no se atrevieron a confrontar la prepotencia de los miembros del partido de gobierno. En cualquier caso, su actitud es claro ejemplo de la debilidad de la institución responsable de organizar y vigilar el desarrollo de los comicios.

La incapacidad, la debilidad y la desidia del propio Tribunal Supremo Electoral contribuyeron lo suyo al desorden. Uno de cada cuatro electores tuvo dificultades para ejercer el sufragio o presenció anomalías diversas - desorganización y falta de información en los centros de votación, otro había votado 
antes por él, desparición de los listados no obstante haber votado en la elección pasada, no correspondencia entre el nombre real y el de las listas-, concentración del servicio de transporte en determinadas zonas de la capital e información sobre el escrutinio deficiente y tardía, pese al despliegue de tecnología y buenas palabras.

El crecimiento del Centro Democrático Unido en estas elecciones es una advertencia seria que no debiera pasar desapercibida a quienes se muestran temerosos de ser identificados con la izquierda.

Ante este cúmulo de irregularidades, los magistrados del Tribunal Supremo Electoral descargaron su responsabilidad en los partidos políticos y en la necesidad de hacer reformas estructurales, pasando por alto que ellos mismos son parte orgánica de ambas cosas. A menos que se hagan reformas orientadas a garantizar que todo adulto cuente con las condiciones mínimas para ejercer su derecho al sufragio, el sistema electoral seguirá deslizándose de forma gradual, pero segura, hacia la obsolescencia. Así, el sistema electoral corre el grave peligro de llegar a convertirse en un obstáculo para el cumplimiento de una de las funciones esenciales de la democracia representativa. Estas irregularidades no son simples casualidades o anormalidades, sino que forman parte integral de la complejidad y exclusividad que caracterizan al sistema electoral salvadoreño actual.

\section{Cuestiones abiertas}

ARENA se apresta a gobernar el país durante cinco años más con muy poca representatividad —el 82 por ciento de la población adulta no votó por dicho partido. No es un buen comienzo para un gobierno que se propone apoyar su gestión en la concertación de alianzas amplias y pluralistas. Esto no será posible si antes el gobierno de Flores no consigue más adhesiones que las recibidas el 7 de marzo, una meta bastante dificil de alcanzar de momento, porque ni él ni el partido ni el sistema político en el que ambos se inscriben han mostrado capacidad para ello. Muchos cambios habrían de ocurrir para que la población respaldara significativamente al nuevo gobierno de ARENA. Por otro lado, la oposición, y en concreto el FMLN, no está en posición como para sacar ventaja de esta falta de representatividad del gobierno de Flores. Mientras el gobierno de ARENA no cambie y/o el FMLN no capitalice la poca representatividad de aquél, El Salvador podría tener más de lo mismo, en el corto y mediano plazo.

ARENA y el FMLN parecieran enfrentar serias limitaciones para ampliar su respectivo caudal de votos. Esta limitación dificulta ampliar la representatividad 
popular que ARENA dice necesitar para gobernar, por un lado, al menos de acuerdo con la tesis central de su discurso de campaña, y por el otro lado, que el FMLN también requiere para impulsar dichos intereses desde el poder ejecutivo. En efecto, los datos indican con bastante seguridad que ARENA ya habría alcanzado su crecimiento máximo, manteniéndose en el poder más por la debilidad de la oposición que por su propia fuerza electoral. Atrapado en el pasado anticomunista y de guerra fría y preocupado por conservar el poder, ARENA dejó pasar la década de los noventa hablando de tiempos nuevos, pero sin que éstos lo afectasen de forma determinante.

La pregunta que surge, entonces, es qué fuerza política desplazará o reemplazará a ARENA en el futuro próximo. Por historia y tradición, ese lugar estaría reservado al FMLN. Sin embargo, el relevo no ocurrirá de manera mecánica. En buena medida, dependerá de cómo el FMLN reaccione a la derrota electoral recién pasada, de que pueda encontrar una identidad de izquierda, revolucionaria y democrática a la vez, y de su capacidad para aglutinar a las fuerzas de la oposición contra ARENA. Esto pasa necesariamente por una administración mejor de sus diferencias internas, por una dirección unitaria y firme al mismo tiempo, y por una opción clara a favor de las mayorías populares - versus una perspectiva meramente electorera. Es indudable que el FMLN crecerá en las preferencias electorales si llega a comprender que no debe esconder -y mucho menos avergonzarse- de su ideología de izquierda. Es su única alternativa, si lo que busca en realidad es disputar la hegemonía política a ARENA.

El crecimiento del Centro Democrático Unido en estas elecciones es una advertencia seria que no debiera pasar desapercibida a quienes se muestran temerosos de ser identificados con la izquierda. Si alguien ha ganado en las elecciones de marzo de 1999, ése es el Centro Democrático Unido, puesto que fue el único participante cuya intención de voto creció de forma rápida y bastante improvisada, cuando todos los demás conservaron o perdieron la posición ya adquirida. La consolidación del Centro Democrático Unido y sus posibilidades para convertirse en la tercera fuerza política que, desde una posición independiente, intervenga de manera determinante en la polarización que mantienen ARENA y el FMLN depende de si la coalición actual se transforma en un partido con una base amplia, de su capacidad para transferir la popularidad de su candidato a una estructura partidaria sólida, de la unificación de las diferentes corrientes que lo integran en la actualidad alrededor de un proyecto común, de la integración de elementos nuevos y jóvenes, y de la superación del oportunismo creciente. A su favor tiene que el liderazgo indiscutible de Zamora es más fuerte que el de la coalición, pero el personalismo que caracteriza a esta clase de conducción política tiene el peligro de convertirse en una desventaja. 
De todas maneras, la reacción de la población ante una alternativa de izquierda es una lección que la dirigencia del FMLN no debe pasar por alto. Otra lección que los partidos políticos debieran asimilar es que las candidaturas no se improvisan. El éxito relativo de Zamora se debe, en gran parte, a su trayectoria de muchos años y a su postura ideológica definida. Los políticos de hoy tienden a subestimar las ventajas de una carrera política larga y destacada y, en cambio, confían más en la imagen creada por los asesores a quienes encargan la comercialización electoral y quienes los hacen adoptar las posturas correctas y el discurso apropiado. En la elección pasada, este recurso no ha funcionado como se esperaba. La mayoría de la población no se sintió interpelada por las ofertas comercializadas en el "mercado electoral".

Otra cuestión que se cierne sobre el espectro político salvadoreño es el surgimiento de un dirigente carismático autoritario y populista. Cuando se pregunta a la población qué podría cambiar El Salvador, las primeras respuestas señalan a ARENA y a esta clase de dirigente. Esta posibilidad ha estado apareciendo de manera persistente en las encuestas de opinión desde hace algún tiempo. No sería remoto entonces que, en un futuro no muy lejano, el sistema tradicional de partidos políticos fuese puesto en jaque por una alternativa de esta clase, tal como sucede en otros países latinoamericanos, en la actualidad.

La clase polírica y gobernante no debiera olvidar que en una sociedad desentendida de la política como la salvadoreńa, los partidos representan a una minoría. Esta tendencia no es nueva, pero se ha venido acentuando a lo largo de la década de los noventa como consecuencia directa de la manera de hacer política en El Salvador. Así se explica el fracaso de la costosa campaña del Tribunal Supremo Electoral, dedicada a invitar a la población a concurrir a las urnas y la contradicción implícita de la cultura neoliberal que mientras, por un lado, promueve la participación de la llamada sociedad civil, por el otro, le cierra espacios y le niega condiciones para hacer efectiva dicha participación.

Aun reconociendo su fuerte carga de protesta masiva, el ausentismo es un mal para El Salvador y la democracia. Conviene que la población concurra masivamente a las urnas para elegir a sus gobernantes, pero para que esto sea posible, hay que proporcionarle las condiciones para ejercer tal derecho $y$ ofrecerle opciones reales y atractivas, que respondan a sus intereses y necesidades. Los partidos políticos y el Tribunal Supremo Electoral, cuyo poder aquéllos detentan, no han hecho nada extraordinario para alimentar la confianza y la credibilidad del cuerpo electoral. Ni siquiera han podido erradicar la desconfianza tradicional en los comicios. La mitad de la población piensa todavía que las elecciones no son confiables ni transparentes y, si además, cree que el país continuará igual, prescindiendo de quien triunfe, la conclusión inevitable es el ausentismo. La complejidad del sistema electoral y las 
irregularidades de la votación en el interior del país sirvieron para constatar una vez más que la apreciación mayoritaria de la población es correcta. El sistema electoral entero adolece de la misma debilidad estructural de las demás instituciones estatales.

Aunque la transición estaría ya concluida, la consolidación democrática está no sólo en pañales, sino que además se encuentra amenazada por la incapacidad del sistema político para hacer que la población, sobre todo la mayoría popular empobrecida, participe de forma significativa en el quehacer nacional. Ciertamente, esa participación debe ir más allá de las elecciones, abarcando otros ámbitos de la vida pública. Pero cuando ni siquiera en el evento más relevante de la democracia hay una participación activa representativa del sentir popular, no queda más que dudar de los avances de una transición que debiera haber impulsado la democratización de El Salvador mucho más allá.

San Salvador, 14 de abril de 1999. 